\title{
The SDM 3 Circle Model: A Literature Synthesis and Adaptation for Shared Decision Making in the Hospital
}

\author{
Stephanie Rennke, MD¹, Patrick Yuan, BA ${ }^{1}$, Brad Monash, MD¹, Rebecca Blankenburg, MD, MPH², lan $\mathrm{Chua}^{1} \mathrm{MD}^{3}$, \\ Stephanie Harman, MD4, Debbie S. Sakai, MD², Adeena Khan, MD¹, Joan F. Hilton, DSc, MPH5, \\ Lisa Shieh, $\mathrm{MD}^{4}$, Jason Satterfield, $\mathrm{PhD}^{1 *}$
}

\begin{abstract}
${ }^{1}$ Department of Medicine, University of California, San Francisco, San Francisco, California; ${ }^{2}$ Department of Pediatrics, Lucile Packard Children's Hospital, Stanford University, Palo Alto, California; ${ }^{3}$ Division of Hospital Medicine, Department of Pediatrics, Children's National Medical Center, George Washington School of Medicine, Washington, DC; ${ }^{4}$ Department of Medicine, Stanford University, Stanford, California; ${ }^{5}$ Department of Epidemiology and Biostatistics, University of California, San Francisco, San Francisco, California.
\end{abstract}

\begin{abstract}
Patient engagement through shared decision-making (SDM) is increasingly seen as a key component for patient safety, patient satisfaction, and quality of care. Current SDM models do not adequately account for medical and environmental contexts, which may influence medical decisions in the hospital. We identified leading SDM models and reviews to inductively construct a novel SDM model appropriate for the inpatient setting. A team of medicine and pediatric hospitalists reviewed the literature to integrate core SDM concepts and processes and iteratively constructed a synthesized draft model. We then solicited broad SDM expert feedback on the draft model for validation and further refinement. The SDM 3 Circle Model identifies 3 core categories of variables that dynamically interact within an "environmental frame." The resulting Venn diagram includes overlapping circles for (1) patient/
\end{abstract}

family, (2) provider/team, and (3) medical context. The environmental frame includes all external, contextual factors that may influence any of the 3 circles. Existing multistep SDM process models were then rearticulated and contextualized to illustrate how a shared decision might be made. The SDM 3 Circle Model accounts for important environmental and contextual characteristics that vary across settings. The visual emphasis generated by each "circle" and by the environmental frame direct attention to often overlooked interactive forces and has the potential to more precisely define, promote, and improve SDM. This model provides a framework to develop interventions to improve quality and patient safety through SDM and patient engagement for hospitalists. Journal of Hospital Medicine 2017;12:1001-1008. Publiched online first October 18, 2017. (C) 2017 Society of Hospital Medicine
Evolving models of medical care emphasize the importance of shared decision-making (SDM) on practical and ethical grounds. ${ }^{1-3}$ SDM is a cognitive, emotional, and relational process in which provider and patient collaborate in a decision after discussing the options, evidence, and potential benefits and harms, while considering the patient's values, preferences, and circumstances. ${ }^{4}$ Categories of decisions include information gathering, pharmacotherapy, therapeutic procedures, consultations and referrals, counseling and precautions (eg, behavior modification, goals of care, end-oflife care), and care transitions (eg, transfer or discharge to home). ${ }^{5}$ Decisions span the continuum of urgency and may be anticipatory or reactive. ${ }^{6}$ The patient's environment ${ }^{7,8}$ and the provider-patient relationship ${ }^{9}$ have been explicitly incorporated into the ideal SDM process.

SDM has been conceptually and empirically linked with evidence-based practice, ${ }^{1}$ although the relationship between

\footnotetext{
*Address for correspondence and reprint requests: Jason Satterfield, PhD, Department of Medicine, University of California, San Francisco, 1701 Divisadero Street, Suite 500, San Francisco, CA, 94115; Telephone: 415-353-2104; Fax: 415-353-7901; E-mail: Jason.Satterfield@ucsf.edu

Additional Supporting Information may be found in the online version of this article.
}

Received: April 12, 2017; Revised: June 15, 2017; Accepted: June 16, 2017 2017 Society of Hospital Medicine DOI 10.12788/jhm.2865
SDM and clinical outcomes is less clear. ${ }^{10,11}$ SDM is desired by patients ${ }^{12}$ and may bolster patient satisfaction, trust, and adherence. ${ }^{13,14}$ Limited evidence suggests SDM could reduce inappropriate treatments and testing, ${ }^{15}$ decrease adverse events, ${ }^{16}$ and promote greater patient safety, ${ }^{17-19}$ but more well-designed studies are needed.

Provider, patient, and contextual factors influence the extent to which SDM occurs. Providers commonly cite time constraints and perceived lack of applicability to certain clinical scenarios or settings. ${ }^{19}$ Providers may also lack training and competency in SDM skills. ${ }^{2}$ Patients may be reluctant to disagree with their provider or fear being mislabeled as "difficult." ${ }^{20}$ When faced with high stakes or emotionally charged decisions, patients' surrogates may prefer to have the provider serve as the sole decision-maker. ${ }^{21}$ Contextually, there may be limited evidence, high clinical stake, or a number of equally beneficial (or harmful) options. ${ }^{22,23}$

Current SDM models guide clinicians in determining when and how to engage in SDM, yet models vary widely. For example, Elwyn's model emphasizes the ethical imperative for SDM and outlines 3 SDM steps: introduce choice, describe options, and help patients explore preferences and make decisions. ${ }^{3}$ Using a multimodal review and clinician-driven feedback, Legaré's "IP-SDM" (Interprofessional Shared Decision Making) model illustrates the roles of the interprofessional team and emphasizes the influence of environmental factors on decision-making. ${ }^{24}$ Recent sys- 
TABLE 1. Examples of differences between inpatient and outpatient shared decision-making

\begin{tabular}{|c|c|}
\hline Outpatient Setting & Inpatient Setting \\
\hline \multicolumn{2}{|c|}{ Timing / Temporality of Decisions } \\
\hline Single office visit/encounter or multiple discrete visits & Series of encounters over the course of hospitalization \\
\hline Time limited to appointment slot with some decisions made over multiple visits & Time variability per daily encounter(s) \\
\hline \multirow[t]{2}{*}{ Healthcare staff interface within appointment window } & Members of healthcare staff and team interface at variable times during the day \\
\hline & Different healthcare staff interface at different periods \\
\hline \multicolumn{2}{|c|}{ Decision-Making Environment } \\
\hline \multirow{2}{*}{$\begin{array}{l}\text { Time to ponder decisions away from the clinical environment after the brief and discrete clinical } \\
\text { encounter }\end{array}$} & Continued frequent conversations about clinical decision \\
\hline & Quick access to variable specialists and members of the same institution's healthcare team (includ- \\
\hline \multirow{2}{*}{$\begin{array}{l}\text { Ability to access second opinions out of healthcare team's institution (including family, PCP, special- } \\
\text { ists) }\end{array}$} & ing nurses, social workers) \\
\hline & Patient in foreign environment for undefined time \\
\hline \multirow{2}{*}{$\begin{array}{l}\text { Quick return to patient's natural environment } \\
\text { Inpatient hospital resources not as readily available (imaging, tests, procedures, hospital consultants }\end{array}$} & Closely monitored patient environment with hospital resources readily available (imaging, tests, \\
\hline & procedures, consultants) \\
\hline Generally, less time pressure to make decision & Constant reminders of medical decision(s) needed for patient \\
\hline \multicolumn{2}{|c|}{ Relationships Between Decision Makers } \\
\hline Decisions for elective or urgent matters & Decisions for elective, urgent, or emergent matters \\
\hline Longer-term relationships with medical home providers & Variable time relationships with shift-work providers (days, nights, weekends) \\
\hline Single encounter relationships for urgent care or overflow visits & Interprofessional provider engagement \\
\hline Single trainee working with provider per patient & $\begin{array}{l}\text { In academic institutions, tendency for larger teams, including multiple trainees per team and poten- } \\
\text { tially multiple teams per patient }\end{array}$ \\
\hline \multicolumn{2}{|c|}{ Common Issues } \\
\hline Limited time per encounter & Limited time per patient during rounds \\
\hline Difficulties with follow-up appointments & Confusion regarding provider roles \\
\hline Difficulties with timeliness (eg, of tests, consults, procedures, etc.) & Unpredictability of provider/personnel visits throughout the day \\
\hline Difficulties with care coordination (PCP, specialists) & Confusion stemming from conflicting opinions of different teams \\
\hline Decision stakeholders may not be present at the discrete visit & Multiple teams involved in patient care activities \\
\hline Recall bias when there are lengthy intervals between encounters & Care discontinuity - resulting from shift-work and changes in medical team \\
\hline Care discontinuity - different providers as part of practice group or team & \\
\hline
\end{tabular}

tematic reviews of SDM models have attempted to identify

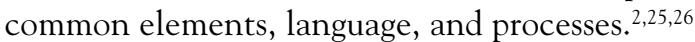

Although published SDM models demonstrate varying emphases-eg, evidence-based medicine, ${ }^{2}$ provider-patient relationships, ${ }^{9}$ interprofessional practices and environmental influences, ${ }^{24}$ or patient contextual factors ${ }^{7,8}$-none specifically address hospitalization and the issues that impact decisions as a patients' clinical condition and care needs change. Studies of SDM in hospitalized patients have relied on either general theoretical frameworks for patient engagement or conceptual models developed specifically for outpatient care. ${ }^{16,27,28}$ Although the key tenets of SDM are relevant across clinical settings, hospitalization introduces a number of unique and highly relevant factors that may influence all aspects of the SDM process. Table 1 provides several examples from the authors of how inpatient and outpatient SDM may differ.

This study reviews leading SDM models to construct a more environmentally and contextually sensitive model that is appropriate for the hospital setting. Although developed with hospital medicine in mind, a synthesized model that attends to environmental and systems context, provider/ team factors, patient factors, and disease/medical variables is highly relevant in any setting where SDM occurs.

\section{METHODS}

We constructed a model that is appropriate for SDM across the care continuum through the following 3-part, iterative group process: (1) a comprehensive literature review of existing SDM models, (2) synthesis and inductive development of a new draft model, and (3) modification of the new model using feedback from SDM experts.

\section{Narrative Literature Review}

We performed a structured, comprehensive literature review ${ }^{29}$ to compare and contrast existing SDM models and frameworks. Leading models and key concepts were first identified using 2 systematic reviews ${ }^{25,26}$ and a comprehensive review. ${ }^{2}$ In order to extend the search to 2016 and include any overlooked articles, a PubMed search was performed using the terms "shared decision-making" or "medical decision-making" AND "model" or "theory" or "framework" for 
TABLE 2. Annotated list of selected SDM studies and models/frameworks

\begin{tabular}{|c|c|}
\hline Author(s) and Citation & Description \\
\hline $\begin{array}{l}\text { Braddock CH, Edwards KA, Hasenberg NM, } \\
\text { Laidley TL, Levinson W. } 1999^{57}\end{array}$ & $\begin{array}{l}\text { Using a cross-sectional descriptive evaluation of audiotaped office visits of primary care and surgeon office visits. Informed (shared) decision-making was } \\
\text { found to be incomplete. Conclusion: More needs to be done to encourage SDM. }\end{array}$ \\
\hline $\begin{array}{l}\text { Braddock III CH, Fihn SD, Levinson W. et al. } \\
1997^{56}\end{array}$ & $\begin{array}{l}\text { Cross-sectional descriptive evaluation of informed decision-making based on audiotaped primary care office encounters. Authors used } 6 \text { criteria to score } \\
\text { informed decision-making and found that a discussion of risks and benefits and patient understanding was infrequent. }\end{array}$ \\
\hline $\begin{array}{l}\text { Charles C, Gafni A, Whelan T. } 1997^{51} \\
\text { Charles C, Gafni A, Whelan T. } 1999^{4}\end{array}$ & $\begin{array}{l}\text { Landmark studies that described a framework for shared decision-making based on a physician-patient partnership in the decision-making process. The } \\
\text { process included sharing of information including treatment preferences and agreement on a decision. }\end{array}$ \\
\hline $\begin{array}{l}\text { Elwyn G, Frosch D, Thomson R, et al. } \\
2012^{3}\end{array}$ & $\begin{array}{l}\text { Authors describe an SDM model for treatment decision in primary care. The model focuses on patient's active involvement in the process, exploration of } \\
\text { expectations and options, teach back and follow up. Three key steps include choice talk, option talk and decision talk. }\end{array}$ \\
\hline Elwyn G, Lloyd A, May C, et al. 2014³7 & $\begin{array}{l}\text { Authors describe the collaborative deliberation model of decision-making based on } 5 \text { communicative efforts of constructive interpersonal engagement, } \\
\text { recognition of alternative actions, comparative learning, preference construction and elicitation and preference integration. The model could apply to } \\
\text { different types of communication in healthcare including motivational interviewing, SDM, goal setting and action planning. }\end{array}$ \\
\hline Epstein RM, Gramling RE. $2013^{53}$ & $\begin{array}{l}\text { Review of the SDM in the context of complex and uncertain situations and the role of preference, relationship and the concept of shared attentional focus. } \\
\text { Authors also include the role of information technology, healthcare teams and health systems in decision-making. }\end{array}$ \\
\hline $\begin{array}{l}\text { Hoffmann TC, Montori VM, Del Mar C. } \\
2014^{1}\end{array}$ & $\begin{array}{l}\text { Authors highlight the interconnection between evidence-based medicine (EBM) and SDM - each is necessary in combination to improve patient care. Calls } \\
\text { for SDM and EBM to be included in practice guidelines and future research. }\end{array}$ \\
\hline $\begin{array}{l}\text { Holzmueller CG, Wu AW, Pronovost PJ. } \\
2012^{36}\end{array}$ & $\begin{array}{l}\text { Framework for physicians to determine patient involvement in decision-making and includes patient-related factors. The framework further delineates } \\
\text { situations when patients should decide and when physicians should decide. }\end{array}$ \\
\hline Kon, AA. $2010^{54}$ & $\begin{array}{l}\text { Commentary describes SDM as a continuum with one end being patient driven and the opposite physician driven with a middle being both as equal } \\
\text { partners. Different decisions and situations call for varying degrees of patient and physician input in the process. }\end{array}$ \\
\hline $\begin{array}{l}\text { Légaré F, Stacey D, Pouliot S, et al. } 2011^{40} \\
\text { Légaré F., Stacey D, Gagnon S. } 2011^{60}\end{array}$ & $\begin{array}{l}\text { The model describes an interprofessional approach to SDM. Each professional works either in collaboration with other providers or sequentially with the } \\
\text { patient. The model includes the role of environment in SDM and includes clarification of values and feasibility of options. }\end{array}$ \\
\hline Makoul G, Clayman ML. $2006^{25}$ & $\begin{array}{l}\text { Literature review of SDM models and propose a model based on } 9 \text { essential elements. The elements include: define/explain problem, present options, } \\
\text { discuss pros/cons, patient preferences/values, patient ability, physician recommendations, checking for understandings, make/defer decision and arrange } \\
\text { follow up. Authors also include ideal elements and general qualities that promote SDM. }\end{array}$ \\
\hline $\begin{array}{l}\text { Moumjid N, Gafni A, Bremond A, et al. } \\
2007^{26}\end{array}$ & $\begin{array}{l}\text { Explores if there is a clear definition of SDM, whether authors provide a definition of SDM when they use the term, and whether they are consistent in } \\
\text { doing so. }\end{array}$ \\
\hline $\begin{array}{l}\text { Muëller-Engelmann M, Keller H, } \\
\text { Donner-Banzhoff N, Krones T. } 2013^{45}\end{array}$ & $\begin{array}{l}\text { This paper investigates current social norms regarding the appropriateness of SDM in different situations. The authors find that SDM is considered most } \\
\text { important in severe illness and chronic condition. SDM was also indicated as necessary when there is more than } 1 \text { therapeutic option without one being } \\
\text { clearly superior. }\end{array}$ \\
\hline Rapley T. $2008^{55}$ & $\begin{array}{l}\text { Describes a framework for how to conceptualize decision-making as an evolving series of encounters over time interfacing with several different individu- } \\
\text { als, knowledge acquisitions and technologies. }\end{array}$ \\
\hline $\begin{array}{l}\text { Stacey D, Légaré F, Pouliot S, et al. } \\
2010^{52}\end{array}$ & $\begin{array}{l}\text { Comprehensive theory analysis of SDM conceptual models to determine how relevant they are to interprofessional collaboration in clinical practice. They } \\
\text { concluded that most SDM models did not utilize an interprofessional approach. This highlights the need for a model that is more inclusive of other health } \\
\text { professionals. }\end{array}$ \\
\hline $\begin{array}{l}\text { Torke AM,Petronio S, Sachs GA, et al. } \\
2012^{34}\end{array}$ & $\begin{array}{l}\text { This article uses literature from medicine, communication studies, and medical ethics to build a conceptual model of the role of communication in deci- } \\
\text { sion-making. Information processing and relationship building were found to be } 2 \text { major elements of interpersonal communication. }\end{array}$ \\
\hline Towle A, Godolphin W. $2006^{59}$ & $\begin{array}{l}\text { Model is developed from proposed physician and patient competencies for learning and teaching SDM. The competencies include developing a physi- } \\
\text { cian-patient partnership, explicit discussion around patient preference and readiness, role of the patient in the decision-making process, developing an } \\
\text { action plan and resolving conflict. }\end{array}$ \\
\hline $\begin{array}{l}\text { Weiner SJ, Schwartz A, Sharma G, et al. } \\
2013^{8}\end{array}$ & $\begin{array}{l}\text { Observational study using a protocol of medical chart audits and audiotaped provider encounters at internal medicine clinics at } 2 \text { VA hospitals to evaluate } \\
\text { for contextualizing care (also called patient-centered decision-making); providers were scored on their ability to incorporate contextual factors such as } \\
\text { barriers to treatment into care planning. The developed protocol could be used to assess physician performance around contextualized decision-making. }\end{array}$ \\
\hline Whitney SN. $2003^{23}$ & $\begin{array}{l}\text { This article proposes a model of medical decisions based on importance and clarity. It also identifies } 3 \text { types of decisions that are less well suited to a } \\
\text { collaborative decision: major decisions with low certainty, minor decisions that have high certainty, and major decisions that have high certainty when } \\
\text { patients and physicians disagree. }\end{array}$ \\
\hline
\end{tabular}

English-language articles from inception to 2016. The search was repeated using Google Scholar to verify results and obtain the number of citations per article as a proxy for impact and saturation. In order to minimize possible search error or selection bias, reference lists in high-impact publications were hand searched to identify additional articles. All abstracts were manually reviewed by 2 independent authors for relevance and later inclusion in our group iterative process. A priori inclusion criteria were limited to provider-patient SDM (ie, not clinical reasoning or making decisions in general) and 
complete descriptions of a conceptual model or framework. Additional publications suggested by experts (eg, perspective pieces or terminology summaries) were also reviewed.

\section{Model Development and Expert Review}

An electronic SDM reference library and annotated bibliography of the selected articles (Table 2) was created to guide the synthesis of SDM models and highlight needed revisions for hospital medicine. In a process similar to Legaré, ${ }^{24}$ a group of 8 pediatric and adult medicine hospitalists, a palliative care physician, a cognitive psychologist, a biostatistician, and 3 medical trainees reviewed the selected SDM publications and models $\mathrm{s}^{30}$ and independently created their own adapted inpatient SDM models. Through an iterative, consensus-building group process, each model was discussed to select key elements or features to be integrated into a synthesized model. This model was guided by principles of social ecological theory, which emphasizes the role of the individual as influenced by and interactive with systems and the environment. ${ }^{31}$

The draft model and a standardized set of questions (supplementary Appendix A) were then emailed to all first and last authors of the reviewed studies (Table 2). Expert responses were compiled, coded, and analyzed independently by 3 coauthors. Inductive coding techniques and a constant comparative approach were used to code the qualitative data. ${ }^{32}$ Preliminary findings were shared among the 3 reviewers and discussed until consensus was reached on emerging themes and implications for the new SDM model and multistep SDM pathway. A master list of suggested revisions was shared with the larger authorship team and the model was refined accordingly.

\section{RESULTS}

Two previously published systematic reviews ${ }^{25,26}$ identified 494 articles, 161 conceptual definitions of SDM, and over 30 separate key concepts. The additional PubMed search garnered 1957 publications (with many overlapping from the systematic reviews). A manual search of the systematic reviews and PubMed abstracts identified 16 unique and complete decision-making models for further review. Hand searches of their citations yielded an additional 6 models for a total of 22 models. ${ }^{3,4,13,23,33-51}$ The majority of excluded articles described specific decision aids and small clinical studies, focused on only one step of the decision-making process, or were not otherwise relevant. The first (SR) and senior authors (JS) reviewed the 22 models for SDM relevance, generalizability, and content saturation, yielding a final sample of 9 SDM models. A subsequent Google Scholar search did not identify any new SDM models but 2 SDM theory papers $^{1,52}$ and 2 commentaries ${ }^{53,54}$ were selected based on influence (ie, number of citations), expert recommendation, or coverage of a novel aspect of SDM. A total of 15 studies (9 SDM models + 6 reviews; Table 2 ) were used by our development team to create a synthesized SDM model. A 10th SDM model ${ }^{55}$ and 3 additional descriptive and normative studies $^{8,56,57}$ were later added based on expert feedback and incorporated into our final SDM 3 Circle Model.

\section{Expert Feedback}

Twenty-one of 27 (78\%) SDM expert authors responded to our e-mail request for feedback. The majority (62\%) agreed with the basic elements of the model, including the environmental frame and the 3 domains. Some respondents viewed SDM as strictly a process between patient and provider independent of the disease, leading to refinement of the medical context category. Several experts emphasized the importance of SDM "set-up," which includes the elicitation of patient preferences in how decisions are made and the extent of patient and/or surrogate involvement.

Several respondents identified time constraints $(\mathrm{N}=2)$, acuity of disease $(\mathrm{N}=3)$, and presence of multiple teams $(\mathrm{N}=6)$ to be the significant factors distinguishing inpatient from outpatient SDM. For some experts, "team" referred to the interprofessional care team, whereas others referred to it as the collaboration among attending physicians and trainees. Experts noted that although the intensity and frequency of inpatient interactions could promote SDM, higher patient acuity and the urgency of decisions could negatively influence SDM and/or the patient's ability to participate. Similarly, the presence of other team members may either impede or promote SDM by either contributing to miscommunication or bringing well-trained SDM experts to the bedside. Financial impact on patients and resource constraints were also noted as relevant. All of these elements have been incorporated into the final SDM 3 Circle Model and multistep SDM Pathway (Supplemental Appendix A and B).

\section{The SDM 3 Circle Model}

The SDM 3 Circle Model comprises 3 categories of SDM barriers and facilitators that intersect within the environmental frame of an inpatient ward or other setting: (1) provider/team, (2) patient/family, and (3) medical context. A Venn diagram visually represents the conceptual overlaps and distinctions among these categories that are all affected by the environment in which they occur (Supplemental Appendix A).

The patient/family circle mirrors prior SDM models that address the role of patient preferences in making decisions, ${ }^{3,4,12}$ with the explicit addition of the roles of families and surrogates as either decision-makers or influencers. This circle includes personal characteristics, such as cognitions (eg, beliefs, attitudes), emotions (eg, anxiety, hope), behaviors (eg, adherence, assertiveness), illness history (ie, subjective experience and understanding of one's own medical history), and related social features (eg, culture, education, literacy, social supports).

Patient factors are not static over time or context. They occur within an environmental setting and are likely to be influenced by concurrent provider and medical variables (the second and third circles). Disease exacerbation leading to hospitalization or transfer to a subacute facility could dramati- 


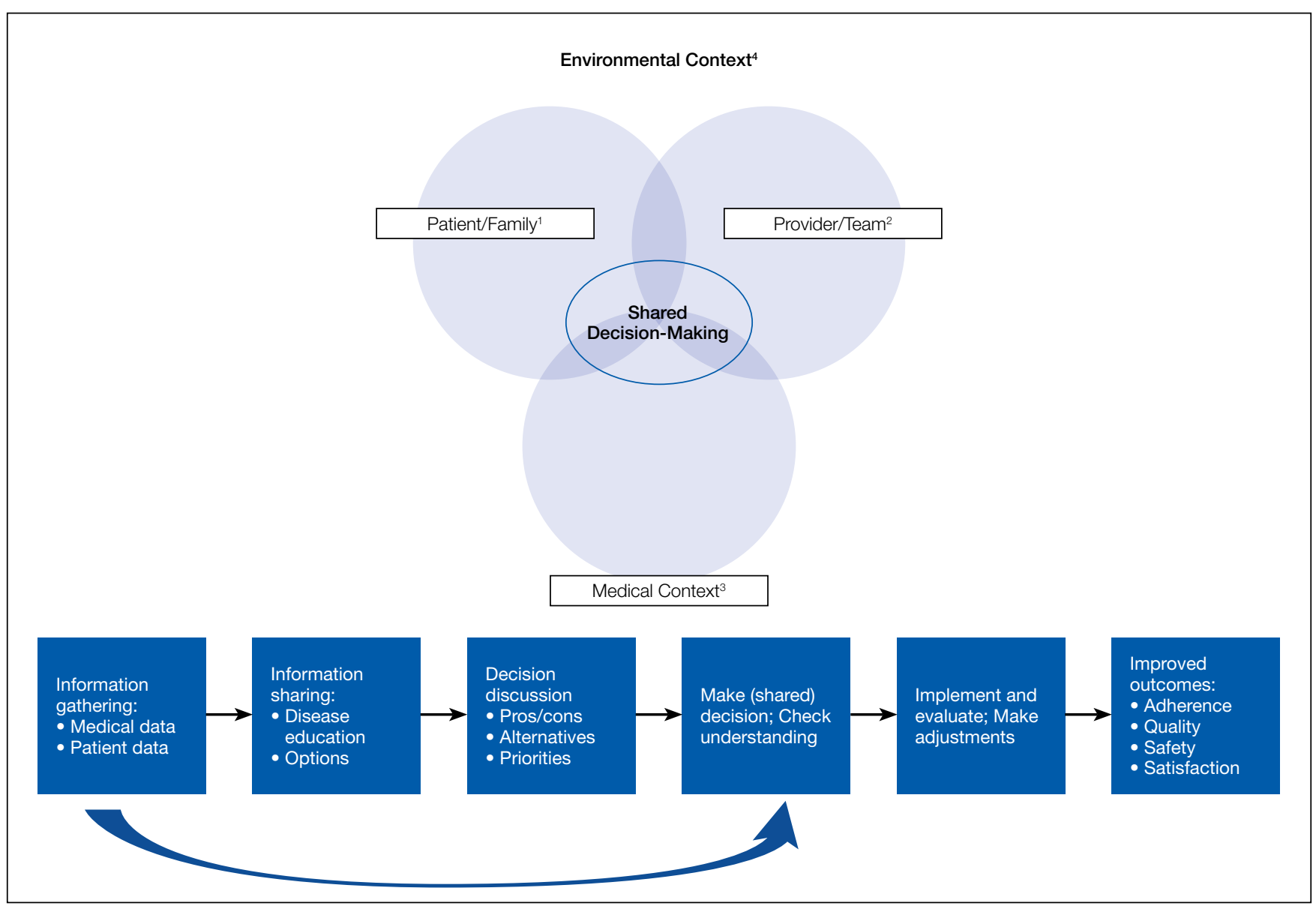

FIG. SDM 3-Circle Conceptual Model and Multistep Shared Decision-Making (SDM) Pathway

NOTE: 'Patient/Family: A patient's ability to engage in SDM reflects one's health (eg, functional and cognitive status) and life circumstances (eg, socio-economic status; presence of a family member to serve as a surrogate). ${ }^{2 P r o v i d e r / ~}$ Team: SDM engagement is influenced by characteristics of an inpatient team (eg, attending physician, trainees, nurse, social workers, case managers, dietitians, therapists) and characteristics of the healthcare providers it comprises (eg, fatigued vs. well-rested; variable familiarity with SDM guidelines). ${ }^{3}$ Medical Context: Some decisions require a patient to provide informed consent (eg, invasive hospital tests and procedures; blood product transfusions); others require a patient to play a fundamental role (eg, adhere to prescription or course of rehabilitation). ${ }^{4}$ Environment: A clinical service (eg, medicine or pediatrics, emergency department, hospital floor or intensive care unit) operates within a hospital (eg, university-based/community-based) located in a community (eg, transportation options) and health system (with varying incentives and priorities). Features of each level can influence the SDM encounter through their bearing on the three domains. ${ }^{*}$ Certain situations may warrant bypassing or limiting the steps of information sharing and decision discussion such as time-sensitive emergencies (e.g. emergency surgery) or if the patient and/or surrogate are uninterested or unable to participate in SDM

cally shift the calculus a patient uses to determine preferences or activate dormant family dynamics. Strong provider-patient rapport (the overlap of patient and provider factors) may influence the development of trust and subsequent decisions. ${ }^{9}$ The type of disease or symptom presentation (circle 3-medical context) may further influence patient factors due to stigma, perceived vulnerability, or assumed prognosis.

The provider/team circle includes both individual and team-based factors falling into similar categories as the patient/family domain, such as cognitions, behavior, and social features; however, these factors include both personal (eg, the provider's personal history, values, and beliefs) and professional (eg, past medical training, decision-making style, past experiences treating a disease) characteristics. Decisions may involve an interprofessional team representing a broad range of personalities and professional values. Decisions and decision-making processes may change over time as team composition changes, as level of provider expertise varies, or as environmental, patient, or disease/illness factors influence providers and teams.
Medical context includes factors related to the disease and the potential ways to evaluate or manage it. Examples of disease factors include acuity, symptoms, course, and prognosis. Most obviously, disease factors will influence the content of risk-benefit discussions but may also affect the SDM process through disease stigma or cultural assumptions about etiology. Disease evaluation factors include the psychometrics of a diagnostic screen, invasive and noninvasive testing, or a range of different preventive or therapeutic interventions. Treatment variables include the available options, costs, and risk of complications. Medical context variables evolve as evidence-based medicine and biomedical knowledge increase and new treatment options emerge.

Each of the 3 circles operates within the same environmental frame, such as an inpatient medicine ward, which itself operates within a hospital and the broader healthcare system. This frame exerts overt and subtle influences on providers, patients, and even the medical context. Features of the environmental frame include culture (eg, values, preferences, social norms), university versus community setting, 
incentives, formularies, quality improvement campaigns, regulations, and technology use.

The dynamic interactivity of the environmental frame and the 3 circles inform the process of SDM and highlight key differences that may occur between care settings. Certain features may predominate in different situations, but all will influence and be influenced by features of other circles during the course of SDM.

\section{Application of the SDM 3 Circle Model}

As shown in the Figure, the multistep SDM pathway begins with information gathering and processing, where the provider solicits medical history as well as patient preferences for decision-making. This "processing" of patient decision-making preferences is less commonly described. The next steps, sharing information and decision discussion, include patient education about the medical issue and available treatments. Discussions may involve the pros/cons of each option, alternative diagnostic or management strategies, and how these decisions fit with a patient's preferences, abilities (eg, health literacy $)^{58}$ and resources, or what has been called "contextualizing care." ${ }^{\prime, 8}$ Framing and other provider behaviors, including the use of decision aids and decision guides, ${ }^{15}$ may influence these conversations. Finally, after gathering, sharing, and discussing information (as influenced by the environment and 3 circles), a medical decision is made and patient understanding is verified. Detailed examples of how this model might be applied are illustrated with case scenarios in supplemental Appendix B.

Although the SDM process is similar across clinical settings, its operationalization varies in important ways for hospital decision-making. In some situations, patients may defer all decisions to their providers or decisions may be considered with multiple providers concurrently. In the hospital, SDM may not be possible, such as in emergency surgery for an obtunded patient or when the patient and surrogate are not available or able to participate in the decision. Therefore, providers may bypass the steps of information sharing and discussion of the decision (big arrow in the Figure and supplemental Appendix B), proceeding directly to decision making.

\section{DISCUSSION}

The SDM 3 Circle Model provides a concise, ecologically valid, contextually sensitive representation of SDM that synthesizes and extends beyond recent SDM models., ${ }^{3,40}$ Each circle represents the forces that influence SDM across settings. Although the multistep SDM pathway occurs similarly in outpatient and inpatient settings, how each step is operationalized and how each "circle" exerts its influence may differ and warrants further consideration throughout the SDM process. For example, hospitalized patients may have greater stress and anxiety, have more family involvement, be more motivated to adhere to treatment, and may be under greater financial and social pressures. Unlike outpatient primary care, patients are less likely to have an existing relationship with their inpatient providers, potentially compromising patient confidence in the provider, and necessitating expeditious trust building.
The SDM 3 Circle Model captures "setting" in both the broader environmental frame and within the provider/team category of variables. The frame also captures health system and broader community variables that may influence the practicality of some medical decisions. Within this essential frame, all 3 categories of patient, provider, and medical context are included as part of the SDM process. A better understanding of their interplay may be of great value for clinicians, researchers, administrators, and policy makers who wish to further study and promote SDM. Both the SDM 3 Circle Model and its accompanying pathway (Figures 1 and 2) highlight opportunities for intervention and research, and may drive quality improvement initiatives to improve clinical outcomes.

\section{Limitations}

We did not perform a new systematic review, potentially omitting lesser-known publications. We mitigated this risk by using recent systematic reviews, searching multiple databases, hand searching citation lists, and making inquiries to SDM experts. Our selection of models used as a foundation for the synthesized model was based on consensus, which included an element of subjective, clinical judgment. Our SDM expert sample was small and limited to authors of the papers we reviewed, potentially restricting the range of viewpoints received. Lastly, the SDM 3 Circle Model highlights key concept areas rather than all possible factors that influence SDM.

\section{CONCLUSIONS}

We present a peer-reviewed, literature-based SDM model capable of accounting for the unique circumstances and challenges of SDM in the hospital. The SDM 3 Circle Model identifies the primary categories of variables thought to influence SDM, places them in a shared environmental frame, and visually represents their interactive nature. A multistep representation of the SDM process further illustrates how the unique features and challenges of hospitalization might exert influence at various points as patients and providers reach a shared decision. As the interrelationships of patient and provider/team, medical context, and the environmental frame in which they occur are better understood, more effective and targeted interventions to promote SDM can be developed and evaluated.

\footnotetext{
Acknowledgments

The authors would like to thank Evans Whitaker for his assistance with the literature review and the Patient Engagement Project volunteers for their support and assistance with data collection.

Disclosure: Financial support for this study was provided entirely by a grant from NIH/NCCIH (grant \#R25 AT006573, awarded to Dr. Jason Satterfield). The funding agreement ensured the authors' independence in designing the study, interpreting the data, writing, and publishing the report. The following authors are employed by the sponsor: Stephanie Rennke, MD, Patrick Yuan, BA, Brad Monash, MD, Rebecca Blankenburg, MD, MPH, Ian Chua, MD, Stephanie Harman, MD, Debbie S. Sakai, MD, Joan F. Hilton, DSc, MPH., and Jason Satterfield, PhD.
} 


\section{References}

1. Hoffmann TC, Montori VM, Del Mar C. The connection between evidence-based medicine and shared decision making. JAMA. 2014;312(13):1295 1296. doi:10.1001/jama.2014.10186.

2. Stiggelbout AM, Pieterse AH, De Haes JC. Shared decision making: Concepts, evidence, and practice. Patient Educ Couns. 2015;98(10):1172-1179. doi:10.1016/j pec.2015.06.022.

3. Elwyn G, Frosch D, Thomson R, et al. Shared decision making: a model for clinical practice. J Gen Intern Med. 2012;27(10):1361-1367. doi:10.1007/s11606-0122077-6.

4. Charles C, Gafni A, Whelan T. Decision-making in the physician-patient encounter: revisiting the shared treatment decision-making model. Soc Sci Med. 1999;49(5):651-661.

5. Ofstad EH, Frich JC, Schei E, Frankel RM, Gulbrandsen P. What is a medical decision? A taxonomy based on physician statements in hospital encounters: a qual itative study. BMJ Open. 2016;6(2):e010098. doi:10.1136/bmjopen-2015-010098.

6. Fowler FJ, Levin CA, Sepucha KR. Informing and involving patients to improve the quality of medical decisions. Health Aff (Millwood). 2011;30(4):699-706. doi:10.1377/hlthaff.2011.0003.

7. Weiner SJ, Kelly B, Ashley N, et al. Content coding for contextualization of care: evaluating physician performance at patient-centered decision making. Med Decis Making. 2014;34(1):97-106. doi:10.1177/0272989X13493146.

8. Weiner SJ, Schwartz A, Sharma G, et al. Patient-centered decision making and health care outcomes: an observational study. Ann Intern Med. 2013;158(8):573 579. doi:10.7326/0003-4819-158-8-201304160-00001

9. Matthias MS, Salyers MP, Frankel RM. Re-thinking shared decision-making: context matters. Patient Educ Couns. 2013;91(2):176-179. doi:10.1016/j. pec.2013.01.006.

10. Clayman ML, Bylund CL, Chewning B, Makoul G. The Impact of Patient Participation in Health Decisions Within Medical Encounters: A Systematic Review. Med Decis Making. 2016;36(4):427-452. doi:10.1177/0272989X15613530.

11. Shay LA, Lafata JE. Understanding patient perceptions of shared decision mak ing. Patient Educ Couns. 2014;96(3):295-301. doi:10.1016/j.pec.2014.07.017.

12. Chewning B, Bylund CL, Shah B, Arora NK, Gueguen JA, Makoul G. Patient preferences for shared decisions: a systematic review. Patient Educ Couns. 2012;86(1):9-18. doi:10.1016/j.pec.2011.02.004.

13. Butterworth JE, Campbell JL. Older patients and their GPs: shared decision making in enhancing trust. Br J Gen Pract. 2014;64(628):e709-e718. doi:10.3399/bjgp14X682297.

14. Joosten EA, DeFuentes-Merillas L, de Weert GH, Sensky T, van der Staak CP, de Jong CA. Systematic review of the effects of shared decision-making on patient satisfaction, treatment adherence and health status. Psychother Psychosom. 2008;77(4):219-226. doi:10.1159/000126073

15. Stacey D, Légare F, Col NF, et al. Decision aids for people facing health treatment or screening decisions. Cochrane Database Syst Rev. 2014;1:CD001431. doi:10.1002/14651858.CD001431.pub4

16. Weingart SN, Zhu J, Chiappetta L, et al. Hospitalized patients' participation and its impact on quality of care and patient safety. Int J Qual Health Care. 2011;23(3):269-277. doi:10.1093/intqhc/mzr002.

17. Mohammed K, Nolan MB, Rajjo T, et al. Creating a Patient-Centered Health Care Delivery System: A Systematic Review of Health Care Quality From the Patient Perspective. Am J Med Qual. 2014;31(1):12-21. doi:10.1177/1062860614545124.

18. Berger Z, Flickinger TE, Pfoh E, Martinez KA, Dy SM. Promoting engagement by patients and families to reduce adverse events in acute care settings: a systematic review. BMJ Qual Saf. 2014;23(7):548-555. doi:10.1136/bmjqs-2012-001769.

19. Légaré F, Ratté S, Gravel K, Graham ID. Barriers and facilitators to implementing shared decision-making in clinical practice: update of a systematic review of health professionals' perceptions. Patient Educ Couns. 2008;73(3):526-535. doi:10.1016/j.pec.2008.07.018.

20. Frosch DL, May SG, Rendle KAS, Tietbohl C, Elwyn G. Authoritarian physicians and patients' fear of being labeled "difficult" among key obstacles to shared decision making. Health Aff (Millwood). 2012;31(5):1030-1038. doi:10.1377/ hlthaff.2011.0576

21. Johnson SK, Bautista CA, Hong SY, Weissfeld L, White DB. An empirical study of surrogates' preferred level of control over value-laden life support decisions in intensive care units. Am J Respir Crit Care Med. 2011;183(7):915-921. doi:10.1164/rccm.201008-1214OC

22. Müller-Engelmann M, Keller H, Donner-Banzhoff N, Krones T. Shared decision making in medicine: The influence of situational treatment factors. Patient Educ Couns. 2011;82(2):240-246. doi:10.1016/j.pec.2010.04.028

23. Whitney SN. A New Model of Medical Decisions: Exploring the Limits of Shared Decision Making. Med Decis Making. 2003;23(4):275-280. doi:10.1177/0272989X03256006.

24. Légaré $\mathrm{F}$, Bekker $\mathrm{H}$, Desroches $\mathrm{S}$, et al. How can continuing professional develop ment better promote shared decision-making? Perspectives from an international collaboration. Implement Sci. 2011;6:68. doi:10.1186/1748-5908-6-68.

25. Makoul G, Clayman ML. An integrative model of shared decision making in medical encounters. Patient Educ Couns. 2006;60(3):301-312. doi:10.1016/j. pec.2005.06.010

26. Moumjid N, Gafni A, Brémond A, Carrère MO. Shared decision making in the medical encounter: are we all talking about the same thing? Med Decis Making. 2007;27(5):539-546. doi:10.1177/0272989X07306779.

27. Hallström I, Elander G. Decision-making during hospitalization: parents' and children's involvement. J Clin Nurs. 2004;13(3):367-375.

28. Ofstad EH, Frich JC, Schei E, Frankel RM, Gulbrandsen P. Temporal characteristics of decisions in hospital encounters: a threshold for shared decision making? A qualitative study. Patient Educ Couns. 2014;97(2):216-222. doi:10.1016/j. pec.2014.08.005

29. Baumeister RF, Leary MR. Writing narrative literature reviews. Rev Gen Psychol. 1997;1(3):311

30. Moody DL. Theoretical and practical issues in evaluating the quality of conceptual models: current state and future directions. Data Knowl Eng. 2005;55(3):243276. doi:10.1016/j.datak.2004.12.005.

31. McLeroy KR, Bibeau D, Steckler A, Glanz K. An ecological perspective on health promotion programs. Health Educ Q. 1988;15(4):351-377.

32. Basics of Qualitative Research | SAGE Publications Inc. https://us.sagepub.com/enus/nam/basics-of-qualitative-research/book235578. Accessed on September 13, 2016.

33. Halley MC, Rendle KA, Frosch DL. A conceptual model of the multiple stages of communication necessary to support patient-centered care. J Comp Eff Res. 2013;2(4):421-433. doi:10.2217/cer.13.46.

34. Torke AM, Petronio S, Sachs GA, Helft PR, Purnell C. A conceptual model of the role of communication in surrogate decision making for hospitalized adults. Patient Educ Couns. 2012;87(1):54-61. doi:10.1016/j.pec.2011.07.027.

35. Falzer PR, Garman MD. A conditional model of evidence-based decision making: Model of evidence-based decision making. J Eval Clin Pract. 2009;15(6):11421151. doi:10.1111/j.1365-2753.2009.01315.x

36. Holzmueller CG, Wu AW, Pronovost PJ. A framework for encouraging patient engagement in medical decision making. J Patient Saf. 2012;8(4):161-164. doi:10.1097/PTS.0b013e318267c56e.

37. Elwyn G, Lloyd A, May C, et al. Collaborative deliberation: a model for patient care. Patient Educ Couns. 2014;97(2):158-164. doi:10.1016/j.pec.2014.07.027.

38. Ruland CM, Bakken S. Developing, implementing, and evaluating decision support systems for shared decision making in patient care: a conceptual model and case illustration. J Biomed Inform. 2002;35(5-6):313-321. doi:10.1016/S15320464(03)00037-6.

39. Shepperd S, Charnock D, Gann B. Helping patients access high quality health information. BMJ. 1999;319(7212):764.

40. Légaré F, Stacey D, Pouliot S, et al. Interprofessionalism and shared decision-making in primary care: a stepwise approach towards a new model. J Interprof Care. 2011;25(1):18-25. doi:10.3109/13561820.2010.490502.

41. Coutu MF, Légaré F, Durand MJ, et al. Operationalizing a Shared Decision Making Model for Work Rehabilitation Programs: A Consensus Process. J Occup Rehabil. 2015;25(1):141-152. doi:10.1007/s10926-014-9532-7.

42. Hölzel LP, Kriston L, Härter M. Patient preference for involvement, experienced involvement, decisional conflict, and satisfaction with physician: a structural equation model test. BMC Health Serv Res. 2013;13:231.

43. Curtis JR, White DB. Practical guidance for evidence-based ICU family conferences. Chest. 2008;134(4):835-843. doi:10.1378/chest.08-0235.

44. Brooks AT, Silverman L, Wallen G. Shared Decision Making: A Fundamental Tenet in a Conceptual Framework of Integrative Healthcare Delivery. Integr Med Insights. 2013;8:29-36. doi:10.4137/IMI.S12783.

45. Müller-Engelmann M, Donner-Banzhoff N, Keller H, et al. When decisions should be shared: a study of social norms in medical decision making using a factorial survey approach. Med Decis Making. 2013;33(1):37-47. doi:10.1177/0272989X12458159.

46. Mccaffery KJ, Shepherd HL, Trevena L, et al. Shared decision-making in Australia. Z Arztl Fortbild Qualitatssich. 2007;101(4):205-211

47. Rubin MA. The Collaborative Autonomy Model of Medical Decision-Making. Neurocrit Care. 2014;20(2):311-318. doi:10.1007/s12028-013-9922-2.

48. McCullough LB. The professional medical ethics model of decision making under conditions of clinical uncertainty. Med Care Res Rev. 2013;70(1 Suppl):141S-158S. doi:10.1177/1077558712461952.

49. Satterfield JM, Spring B, Brownson RC, et al. Toward a Transdisciplinary Model of Evidence-Based Practice. Milbank Q. 2009;87(2):368-390.

50. Moore JE, Titler MG, Kane Low L, Dalton VK, Sampselle CM. Transforming Patient-Centered Care: Development of the Evidence Informed Decision Making through Engagement Model. Womens Health Issues. 2015;25(3):276-282. doi:10.1016/j.whi.2015.02.002. 
51. Charles C, Gafni A, Whelan T. Shared decision-making in the medical encounter: what does it mean? (or it takes at least two to tango). Soc Sci Med. 1997;44(5):681-692

52. Stacey D, Légaré F, Pouliot S, Kryworuchko J, Dunn S. Shared decision making models to inform an interprofessional perspective on decision making: a theory analysis. Patient Educ Couns. 2010;80(2):164-172. doi:10.1016/j.pec.2009.10.015.

53. Epstein RM, Gramling RE. What is shared in shared decision making? Complex decisions when the evidence is unclear. Med Care Res Rev. 2013;70(1 Suppl):94S-112S. doi: $10.1177 / 1077558712459216$.

54. Kon AA. The shared decision-making continuum. JAMA. 2010;304(8):903-904 doi:10.1001/jama.2010.1208.

55. Rapley T. Distributed decision making: the anatomy of decisions-in-action. Sociol Health Illn. 2008;30(3):429-444. doi:10.1111/j.1467-9566.2007.01064.x.

56. Braddock CH 3rd, Fihn SD, Levinson W, Jonsen AR, Pearlman RA. How doctors and patients discuss routine clinical decisions. Informed decision making in the outpatient setting. J Gen Intern Med. 1997;12(6):339-345.

57. Braddock CH 3rd, Edwards KA, Hasenberg NM, Laidley TL, Levinson W. Informed decision making in outpatient practice: time to get back to basics. JAMA. 1999;282(24):2313-2320.

58. Smith SK, Dixon A, Trevena L, Nutbeam D, McCaffery KJ. Exploring patient involvement in healthcare decision making across different education and functional health literacy groups. Soc Sci Med. 2009;69(12):1805-1812. doi:10.1016/j.socscimed.2009.09.056.

59. Towle A, Godolphin W, Grams G, Lamarre A. Putting informed and shared decision making into practice. Health Expect. 2006;9(4):321-332. doi:10.1111/j.1369. 7625.2006.00404.x.

60. Légaré F, Stacey D, Gagnon S, et al. Validating a conceptual model for an interprofessional approach to shared decision making: a mixed methods study. J Eval Clin Pract. 2011;17(4):554-564. doi: 10.1111/j.1365-2753.2010.01515.x. 